\title{
Hubungan Derajat Keasaman Cairan Lambung dengan Derajat Dispepsia pada Pasien Dispepsia Fungsional
}

\author{
Emil Prasetyo Muhammad ${ }^{1}$, Arina Widya Murni ${ }^{2}$, Delmi Sulastri ${ }^{3}$, Saptino Miro $^{2}$
}

\begin{abstract}
Abstrak
Hipersekresi asam lambung dianggap penting sebagai salah satu mekanisme patologis dispepsia fungsional. Hipersekresi asam lambung dapat meningkatkan sekresi pepsin yang dapat menimbulkan kerusakan mukosa lambung pada dispepsia fungsional. Tujuan penelitian ini adalah menentukan hubungan derajat keasaman cairan lambung dengan derajat dispepsia yang dialami pasien dispepsia fungsional. Penelitian ini merupakan studi analitik dengan disain cross sectional yang dilakukan pada 35 sampel pasien dispepsia fungsional dengan teknik consecutive sampling di RSUP DR. M.Djamil Padang mulai Juli sampai Oktober 2014. Analisis data dilakukan secara komputerisasi menggunakan uji chi-square. Hasil penelitian didapatkan 51.4\% pasien dispepsia fungsional memiliki derajat keasaman cairan lambung hyperacidity, $57.1 \%$ menderita dispepsia derajat sedang-berat, dan menunjukkan hubungan yang cukup kuat dengan tarif signifikansi $(p) 0.029(p<0.05)$. Terdapat hubungan bermakna antara derajat keasaman cairan lambung dengan derajat dispepsia pada pasien dispepsia fungsional. Peningkatan derajat keasaman cairan lambung berbanding lurus dengan derajat dispepsia pada pasien dispepsia fungsional.
\end{abstract}

Kata kunci: keasaman cairan lambung, derajat dispepsia, dispepsia fungsional

\begin{abstract}
Gastric acid hypersecretion is considered important as one of the pathological mechanisms of functional dyspepsia. Gastric acid hypersecretion can increase the secretion of pepsin which can cause gastric mucosal damage in functional dyspepsia. The objective of this study was to determine the correlation of gastric juice acidity with dyspepsia level experienced by functional dyspepsia patients. This study was a analytic study with cross sectional design applied on 35 samples of functional dyspepsia patients with non-probability consecutive sampling technique at RSUP DR. M. Djamil Padang from July to October 2014. The data were computerized analyzed using chi-square test. The results showed $51.4 \%$ of patients with functional dyspepsia had hyperacidity gastric juice, $57.1 \%$ had moderate-tosevere dyspepsia level, and show a strong enough correlation with the rate of significance $0.029(p<0.05)$. There was a significant correlation between the gastric juice acidity with dyspepsia level of functional dyspepsia patients. Increase of gastric juice acidity is proportional to the dyspepsia level in functional dyspepsia patients.
\end{abstract}

Keywords::gastric juice acidity, dyspepsia level, functional dyspepsia

Affiliasi penulis: 1. Pendidikan Dokter FK UNAND (Fakultas Kedokteran Universitas Andalas Padang), 2. Bagian IImu Penyakit Dalam FK UNAND, 3. Bagian Gizi FK UNAND.

Korespondensi: Emil Prasetyo Muhammad, Email:

emilmuhammad@ymail.com Telp: +62 85382250330

\begin{abstract}
PENDAHULUAN
Dispepsia mengacu pada sekelompok gejala yang berasal dari saluran cerna meliputi nyeri epigastrium, rasa terbakar di epigastrium, rasa penuh setelah makan, cepat kenyang, kembung, mual, muntah, dan sendawa. ${ }^{1}$ Berdasarkan penyebabnya,
\end{abstract}


dibagi menjadi dispepsia organik dan dispepsia fungsional yang sarana penunjang diagnostik tidak dapat memperlihatkan adanya gangguan struktural. ${ }^{2}$

Angka prevalensi dispepsia fungsional bervariasi antara 11\%-29.2\%. Di Norwegia, dari 2027 orang dewasa yang setuju diendoskopi, didapatkan $14.7 \%$ menderita dispepsia fungsional. Prevalensi dispepsia fungsional juga cukup tinggi di Asia. Di Taiwan, 23.8\% dari 2018 orang dewasa yang dilakukan pemeriksaan Eosophago Gastro Duodenoskop (EGD) mengalami dispepsia fungsional. ${ }^{3}$ Pada sebuah penelitian di Singapura, dari 5066 pasien yang mengalami dispepsia 79.5\% diantaranya menderita dispepsia fungsional. ${ }^{4} \mathrm{Di}$ Indonesia, menurut studi berbasiskan populasi pada tahun 2007, ditemukan peningkatan prevalensi dispepsia fungsional dari 1,9\% pada tahun 1988 menjadi $3,3 \%$ pada tahun 2003. Pada tahun 2010, dilaporkan dispepsia fungsional memiliki tingkat prevalensi $5 \%$ dari seluruh kunjungan ke sarana layanan primer. $^{5}$ Tahun 2012 di Sumatera Barat, angka kejadian dispepsia selain penyakit tukak lambung, tukak duodenum, gastritis, duodenitis, dan penyakit esofagus lambung duodenum lainnya adalah sebesar $1,9 \%$, sehingga menempati urutan pertama dari keseluruhan penyakit gastrointestinal serta urutan keempat tertinggi dari semua penyakit yang dilaporkan ke Dinas Kesehatan Provinsi Sumatera Barat terutama dari RSUP M.Djamil Padang. ${ }^{6}$

Salah satu mekanisme patologis dari dispepsia fungsional adalah gangguan keasaman cairan lambung. Beberapa penelitian telah menunjukkan bahwa derajat keasaman cairan lambung pada mayoritas pasien dispepsia fungsional adalah normal, tetapi perkembangan terbaru mendapatkan terdapat sekresi asam yang abnormal serta penurunan respon motor duodenum saat asam timbul. ${ }^{7}$

Dampak dari dispepsia fungsional jelas berpengaruh terhadap kualitas hidup pasien. Selain dari gejala dispepsia yang muncul, pasien juga mempunyai faktor derajat keasaman cairan lambung yang perlu diatasi.

Angka kejadian penyakit dispepsia fungsional di dunia bahkan di Indonesia yang tinggi dan masih minimnya data mendalam tentang dispepsia fungsional di Sumatera Barat, maka perlu dilakukan penelitian lebih lanjut tentang dispepsia fungsional. Tujuan penelitian ini adalah menentukan hubungan derajat keasaman cairan lambung dengan derajat dispepsia pada pasien dispepsia fungsional.

\section{METODE}

Penelitian dilakukan di RSUP Dr. M. Djamil Padang dari Juli sampai Oktober 2014. Sampel dalam penelitian ini sebanyak 35 orang yang merupakan pasien dispepsia fungsional dan memenuhi kriteria inklusi dan eksklusi. Pemilihan sampel dilakukan secara consecutive sampling non probability. Instrumen penelitian yang digunakan adalah Eosophago Gastro Duodenoskop (EGD) untuk menentukan jenis dispepsia, $\mathrm{pH}$ meter untuk mengukur nilai $\mathrm{pH}$ cairan lambung dan skor dispepsia untuk menentukan derajat dispepsia. Data yang diperoleh diolah secara univariat dan bivariat dengan komputerisasi. Analisis bivariat digunakan uji chisquare dengan nilai kemaknaan $\mathrm{p}<0.05$.

\section{HASIL}

Tabel 1 menunjukkan distribusi sampel berdasarkan karakteristik yaitu sampel terbanyak berada pada kelompok umur lebih dari 45 tahun $(37.1 \%)$, perempuan lebih banyak dibandingkan lakilaki $(54.3 \%)$ dan yang bekerja lebih banyak daripada yang tidak bekerja $(68.6 \%)$.

Tabel 1. Distribusi sampel berdasarkan karakteristik

\begin{tabular}{lcc}
\hline Karakteristik & $\mathbf{f}$ & $\%$ \\
\hline Umur & 8 & \\
$17-25$ tahun & 6 & 22.9 \\
$26-35$ tahun & 8 & 17.1 \\
$36-45$ tahun & 13 & 22.9 \\
$>45$ tahun & & 37.1 \\
Jenis kelamin & 16 & \\
Laki-laki & 19 & 45.7 \\
Perempuan & & 54.3 \\
Pekerjaan & 24 & 68.6 \\
Bekerja & 11 & 31.4 \\
Tidak Bekerja & & \\
\hline
\end{tabular}

Gambar 1 menunjukkan paling banyak dispepsia fungsional yaitu 111 orang (56.35\%). 
$43.65 \%$

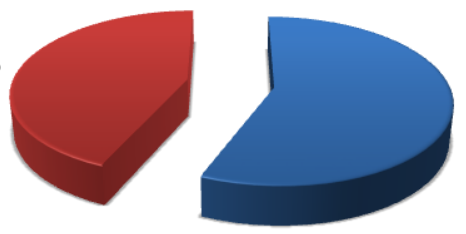

$56.35 \%$

Dispepsia Fungsional

Dispepsia Organik

Gambar 1. Distribusi pasien dispepsia fungsional dan organik

Gambar 2 menunjukkan sebagian besar mempunyai cairan lambung dengan derajat keasaman hiperacidity yaitu sebanyak 18 orang (51.4\%).

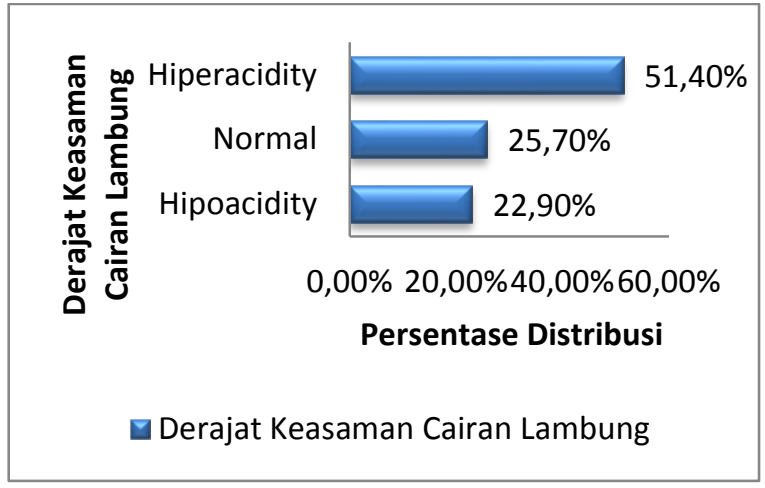

Gambar 2. Distribusi sampel berdasarkan derajat keasaman cairan lambung

Gambar 3 menunjukkan bahwa berdasarkan skor dispepsia, lebih dari setengah sampel mengeluhkan dispepsia derajat sedang-berat yaitu sebanyak 20 orang (57.1\%).

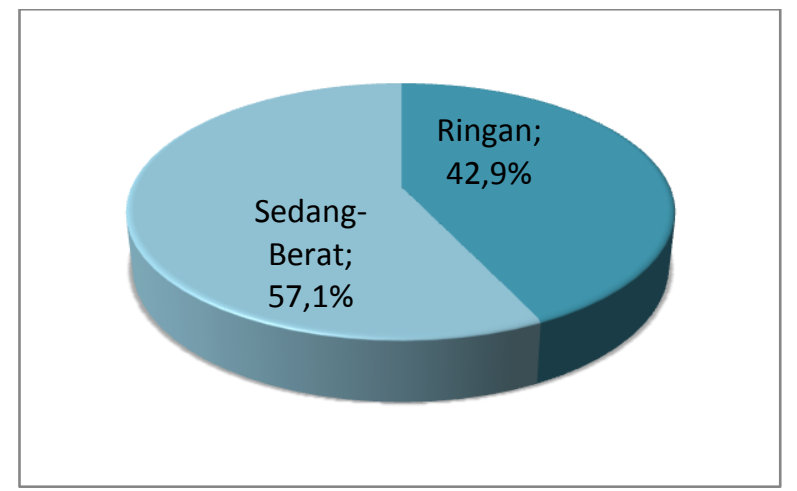

Gambar 3. Distribusi sampel berdasarkan derajat dispepsia
Tabel 2 menunjukkan bahwa dari 18 pasien dengan derajat keasaman cairan lambung hyperacidity lebih banyak menderita dispepsia derajat sedangberat yaitu sebanyak 10 orang (55.6\%) dibanding derajat ringan sebanyak 8 orang (44.4\%). Hasil analisis menunjukkan hubungan signifikan dengan tarif signifikansi $(p<0.05)$. Terdapat hubungan yang bermakna antara derajat keasaman cairan lambung dengan derajat dispepsia pada pasien dispepsia fungsional.

Tabel 2. Hubungan derajat keasaman cairan lambung dengan derajat dispepsia

\begin{tabular}{|c|c|c|c|c|c|c|c|}
\hline \multirow{4}{*}{$\begin{array}{c}\text { Derajat } \\
\text { Keasa } \\
\text { man }\end{array}$} & \multicolumn{4}{|c|}{ Derajat Dispepsia } & \multicolumn{2}{|c|}{ Total } & \multirow{4}{*}{$\mathbf{p}$} \\
\hline & \multirow{2}{*}{\multicolumn{2}{|c|}{ Ringan }} & \multirow{2}{*}{\multicolumn{2}{|c|}{$\begin{array}{c}\text { Sedang- } \\
\text { Berat }\end{array}$}} & & & \\
\hline & & & & & & & \\
\hline & $f$ & $\%$ & $f$ & $\%$ & $f$ & $\%$ & \\
\hline \multicolumn{8}{|l|}{ Hipo } \\
\hline acidity & 6 & 75.0 & 2 & 25.0 & 8 & 100 & \\
\hline Normal & 1 & 11.1 & 8 & 88.9 & 9 & 100 & 0.029 \\
\hline \multicolumn{8}{|l|}{ Hiper } \\
\hline acidity & 8 & 44.4 & 10 & 55.6 & 18 & 100 & \\
\hline Total & 15 & 42.9 & 20 & 57.1 & 35 & 100 & \\
\hline
\end{tabular}

\section{PEMBAHASAN}

Pada Gambar 1 dapat dilihat bahwa kejadian dispepsia fungsional lebih banyak terjadi dibandingkan dispepsia organic. .Menurut literatur, kejadian dispepsia fungsional menempati angka yang lebih tinggi dibandingkan dengan dispepsia organik. Pada sebuah penelitian terhadap 854 orang dengan gejala dispepsia, didapatkan $76.4 \%$ menderita dispepsia fungsional dan $23.6 \%$ menderita dispepsia organik. ${ }^{8}$ Pada sebuah penelitian terhadap 782 pasien dengan gejala dispepsia di Shanghai, 69.4\% diantaranya menderita dispepsia fungsional sementara $30.6 \%$ menderita dispepsia organik. ${ }^{9}$

Tingkat keasaman cairan lambung dapat diukur berdasarkan $\mathrm{pH}$ cairan lambung. Nilai $\mathrm{pH}$ cairan lambung normal adalah $2-3,5$, dikatakan hypoacidity bila $\mathrm{pH}$ lebih dari 3,5 dan hyperacidity bila $\mathrm{pH}$ kurang dari 2. ${ }^{10}$ Pada penelitian ini, cairan lambung pasien diambil melalui selang yang dimasukkan melalui 
eosophagogastroduodenoskop pada saat dilakukan

EGD. Cairan lambung pasien langsung diukur menggunakan elektroda $\mathrm{pH}$ meter. Hasil penelitian menunjukkan bahwa derajat keasaman cairan lambung pasien dispepsia fungsional dominan pada derajat hyperacidity, diikuti oleh normal dan hypoacidity masing-masing 51.4\%, 25.7\%, dan $22.9 \%$.

Pada penelitian terhadap 20 pasien dispepsia fungsional di Jepang, lebih banyak derajat keasaman cairan lambung hyperacidity $60 \%$ diikuti normalhypoacidity sebanyak 40\%. ${ }^{11}$ Pada penelitian ini telah didapatkan bahwa peningkatan keasaman cairan lambung lebih sering terjadi pada pasien dispepsia fungsional. Hal ini terkait dengan hipersekresi asam lambung sebagai salah satu mekanisme patologis pada dispepsia fungsional.

Gambar 3 dapat dilihat bahwa derajat dispepsia terbanyak adalah dispesia derajat sedang-berat sebesar $57.1 \%$, sedangkan dispepsia derajat ringan ditemukan sebanyak $42.9 \%$. Hasil serupa didapatkan pada penelitian sebelumnya terhadap 55 pasien dispepsia fungsional di Italia, ditemukan pasien dengan dispepsia derajat sedang-berat sebesar $80 \%$ dan dispepsia derajat ringan sebesar $20 \%{ }^{12}$

Temuan ini menunjukkan bahwa pada pasien dispepsia fungsional lebih banyak ditemukan gejala dispepsia derajat sedang-berat. Hal ini bisa disebabkan oleh patofisiologi dispepsia fungsional yang melibatkan banyak faktor sehingga munculan gejala lebih berat disamping rendahnya ambang rangsang nyeri yang diakibatkan oleh stres pada pasien dispepsia fungsional.

Hasil analisis uji statistik menggunakan uji Pearson chi-square. Nilai signifikannya pada penelitian ini adalah 0.029 yang berarti $\mathrm{p}<0.05$, sehingga hipotesis yang menyatakan "Terdapat hubungan antara derajat keasaman cairan lambung dengan derajat dispepsia pada pasien dispepsia fungsional" diterima dan memiliki hubungan yang signifikan.

Penelitian ini belum pernah dilakukan sebelumnya, tetapi bila dihubungkan keasaman cairan lambung dengan dispepsia fungsional, maka sesuai dengan pendapat tentang hipersekresi asam akan mengakibatkan sekresi pepsin semakin meningkat.
Daya perusak pepsin yang semakin tinggi menimbulkan peradangan mukosa, kerusakan mukosa, submukosa, dan bahkan lapisan yang lebih dalam lagi. Berbagai kerusakan lapisan inilah yang membuat munculnya gejala dispepsia yang semakin berat seiring dengan semakin tingginya derajat keasaman cairan lambung. ${ }^{13}$

\section{KESIMPULAN}

Terdapat hubungan antara derajat keasaman cairan lambung dengan derajat dispepsia pada pasien dispepsia fungsional.

\section{DAFTAR PUSTAKA}

1. Miwa H, Ghoshal UC, Gonlachanvit S, Gwee KA, Ang TL, Chang FY, et al. Asian consensus report on functional dyspepsia. Journal of Neurogastroenterology and Motility. 2012;18(2):150-68.

2. Djojoningrat D. Dispepsia fungsional. Dalam: Sudoyo AW, Setiyohadi B, Alwi I, Simadibrata $M$, Setiati S, editor (penyunting). Buku ajar ilmu penyakit dalam. Jakarta: Balai Penerbit FK UI; 2009. hlm. 529-32.

3. Mahadeva S, Goh KL. Epidemiology of functional dyspepsia: a global perspective. World Journal of Gastroenterology. 2006;12(17):2661-6.

4. Ghoshal UC, Singh R, Chang FY, Hou X, Wong BCY, Kachintorn $U$. Epidemiology of uninvestigated and functional dyspepsia in Asia: facts and fiction. Journal of Neurogastroenterology and Motility. 2011;17(3): 235-44.

5. Abdullah M, Gunawan J. Dispepsia. CDK-197. 2012;39(9):647-51.

6. Dinas Kesehatan Provinsi Sumatera Barat. Laporan morbiditas pasien rawat inap RS provinsi 2011-2012. Padang: Dinkes Sumatera Barat; 2013

7. Voiosu TA, Giurcan R, Voiosu AM, Voiosu MR. Functional dyspepsia today. Maedica - A Journal of Clinical Medicine. 2013;8(1):68-74.

8. Sander GB, Mazzoleni LE, Francesconi CFM, Balbinotto G, Mazzoleni F, Wortman AC. Influence of organic and functional dyspepsia on work productivity: The heroes-dip study. Value in Health - Elsevier Inc. 2011;14:suppl:126-9. 
9. Li XB, Liu WZ, Ge ZZ, Zhang DR, Zhao YJ, Dai J, et al. Analysis of clinical characteristics of dyspeptic symptoms in Shanghai patients. Chin $\mathrm{J}$ Dig Dis. 2005;6(2): 62-7.

10. Lu PJ, Hsu PI, Chen CH, Hsiao M, Chang WC, Tseng $\mathrm{HH}$, et al. Gastric juice acidity in upper gastrointestinal diseases. World Journal og Gastroenterology. 2010;43(16):5496-501.

11. Ito G, Kaneko E, Sakakibara T, Takeuchi Y, Kitahara $\mathrm{H}$, Kobashi $\mathrm{H}$, et al. The $\mathrm{pH}$ measurement of fasting gastric juice in acute gastric mucosal lesions. Dig Endosc. 1989;1(1):10-7.

12. Zagari RM, Law GR, Fuccio L, Cennamo V, Gilthorpe MS, Forman D, et al. Epidemiology of functional dyspepsia and subgroups in Italian general population: an endoscopic study. Gastroenterology. 2010;138(4):1302-11.

13. Kolopaking MS. Patofisiologi peran hipersekresi asam dan pepsin pada sindroma dispepsia. Jakarta. Dispepsia Sains dan Aplikasi Klinik PIP IPD FKUI; 2005. hlm.45-54. 